\title{
PENERAPAN EDUGAME INTERAKTIF UNTUK PENGENALAN PAKAIAN ADAT NASIONAL INDONESIA
}

\author{
Dwi Nugraheny \\ Program Studi Teknik Informatika \\ Sekolah Tinggi Teknologi Adisucipto, Yogyakarta \\ Email: henynug@gmail.com \\ Ayuningtias Destiranti \\ Program Studi Teknik Informatika \\ Sekolah Tinggi Teknologi Adisucipto, Yogyakarta \\ Email: informatika@stta.ac.id
}

\begin{abstract}
ABSTRAK
Edugame interaktif merupakan media pendidikan yang banyak digunakan di jaman sekarang, dengan visualisasi yang menarik, sehingga masyarakat luas dengan mudah mengetahui informasi yang disampaikan. Edugame interaktif pengenalan pakaian adat nasional indonesia diharapkan dapat menjadi media pembelajaran dan berkreatifitas, sehingga mempermudah pengguna dalam memahami Pakaian Adat Nasional. Edugame interaktif ini dikembangkan dengan memakai Adobe Flash dan bahasa pemrograman action script. Hasil yang sudah diperoleh dari pengujian menggunakan kuisioner adalah $77,13 \%$, dan dapat disimpulkan bahwa aplikasi edugame interaktif pengenalan pakaian adat Nasional Indonesia masuk ke kriteria "baik".
\end{abstract}

Kata kunci: edugame, interaktif, adobe flash, pakaian adat nasional.

\begin{abstract}
Interactive Edugame is an educational media are widely used in today, with interesting visualization, so that the public easily identify the information submitted. Interactive Edugame introduction of the National Indigenous Apparel Indonesia can be a medium of learning and creativity, so that is making user easier to understand the National Indigenous Apparel. Interactive Edugame developed using Adobe Flash and action script programming language. The results already obtained from tests using questionnaires is $77.13 \%$, it can be concluded that the application interactive edugame introduction of the National Indigenous Apparel Indonesia entered "good" criteria.
\end{abstract}

Keywords: edugame, interactive, adobe flash, national indigenous apparel.

\section{PENDAHULUAN}

Ilmu pengetahuan dan teknologi dewasa ini berkembang sangat cepat, khususnya di bidang teknologi informasi, yang mendukung dalam perkembangan sektor-sektor lainnya, seperti perdagangan, pendidikan, komunikasi, perindustrian, pariwisata, dan lain sebagainya. Salah satu fungsi teknologi informasi bagi sektor komunikasi yaitu sebagai media pendidikan, sebagai contoh salah satu penerapan teknologi multimedia dalam bidang pendidikan yaitu dalam bentuk pengenalan permainan interaktif dengan media digital.

Perkembangan teknologi informasi pada berbagai bidang, baik itu dari sisi perangkat lunak maupun perangkat komputer khususnya pada bidang multimedia. Salah satu perangkat lunak yang dikembangkan dan mendukung pembuatan aplikasi multimedia adalah adobe flash. Perangkat lunak tersebut dapat digunakan untuk membuat sebuah game maupun animasi. Edukasi tidak hanya berupa pelajaran. Penggunaan game sebagai sarana pendidikan sebetulnya bukan hal yang salah, karena game bersifat entertain atau menghibur[1].

Game interaktif merupakan media pendidikan yang banyak digunakan di jaman sekarang, dengan visualisasi yang menarik, sehingga masyarakat luas dengan mudah mengetahui informasi yang disampaikan. Fungsi game interaktif ini adalah sebagai media komunikasi atau penyampaian informasi melalui media digital. Pembuatan game interaktif ini, berguna untuk memberi pengenalan dan pengetahuan tentang pakaian adat nasional. Edugame ini juga dapat menjadi media pembelajaran dan 
berkreatifitas bagi anak-anak ataupun pengguna umum sehingga mempermudah dalam mengenal dan memahami pengetahuan pakaian adat nasional.

\section{METODOLOGI PENELITIAN}

\subsection{Pengertian Game Edukasi (Edugame)}

Game edukasi (Edugame) adalah game digital yang dirancang untuk pengayaan pendidikan mendukung pengajaran dan pembelajaran, menggunakan teknologi multimedia interaktif [2]. Menurut Hurd dan Jenuings, perancang yang baik haruslah memenuhi kriteria dari education game itu sendiri [2]. Berikut ini adalah beberapa kriteria dari sebuah education game, yaitu:

a. Nilai Keseluruhan (Overall Value). Nilai keseluruhan dari suatu game terpusat pada desain dan panjang durasi game. Aplikasi ini dibangun dengan desain yang menarik dan interaktif. Untuk penentuan panjang durasi,aplikasi ini menggunakan fitur timer.

b. Kemampuan penggunaan (Usability). Mudah digunakan dan diakses adalah poin penting bagi pembuat game. Aplikasi ini merancang sistem dengan interface yang user friendly sehingga user dengan mudah dapat mengakses aplikasi.

c. Keakuratan (Accuracy) Keakuratan diartikan sebagai bagaimana kesuksesan model/gambaran sebuah game dapat dituangkan ke dalam percobaan atau perancangannya. Perancangan aplikasi ini harus sesuai dengan model game pada tahap perencanaan.

d. Kesesuaian (Appropriateness) Kesesuaian dapat diartikan bagaimana isi dan desain game dapat diadaptasikan terhadap keperluan user dengan baik. Aplikasi ini menyediakan menu dan fitur yang diperlukan user untuk membantu pemahaman user dalam menggunakan aplikasi.

e. Relevan (Relevance) Relevan artinya dapat mengaplikasikan isi game ke target user. Agar dapat relevan terhadap user, sistem harus membimbing mereka dalam pencapaian tujuan pembelajaran. Karena aplikasi ini ditujukan untuk anak-anak, maka desain antarmuka harus sesuai dengan nuansa anak-anak, yaitu menampilkan warna-warna yang ceria.

f. Objektifitas (Objectives) Objektifitas menentukan tujuan user dan kriteria dari kesuksesan atau kegagalan. Dalam aplikasi ini objektivitas adalah usaha untuk mempelajari hasil dari permainan.

g. Umpan Balik (Feedback) Untuk membantu pemahaman user bahwa permainan (performance) mereka sesuai dengan objek game atau tidak, feedback harus disediakan. Aplikasi ini menyajikan animasi dan efek suara yang mengindikasikan kesuksesan atau kegagalan.

\subsection{Tahap-Tahap Pembuatan}

Tahap-tahap pembuatan game edukasi (edugame) interaktif untuk pengenalan pakaian adat nasional Indonesia ini adalah sebagai berikut:

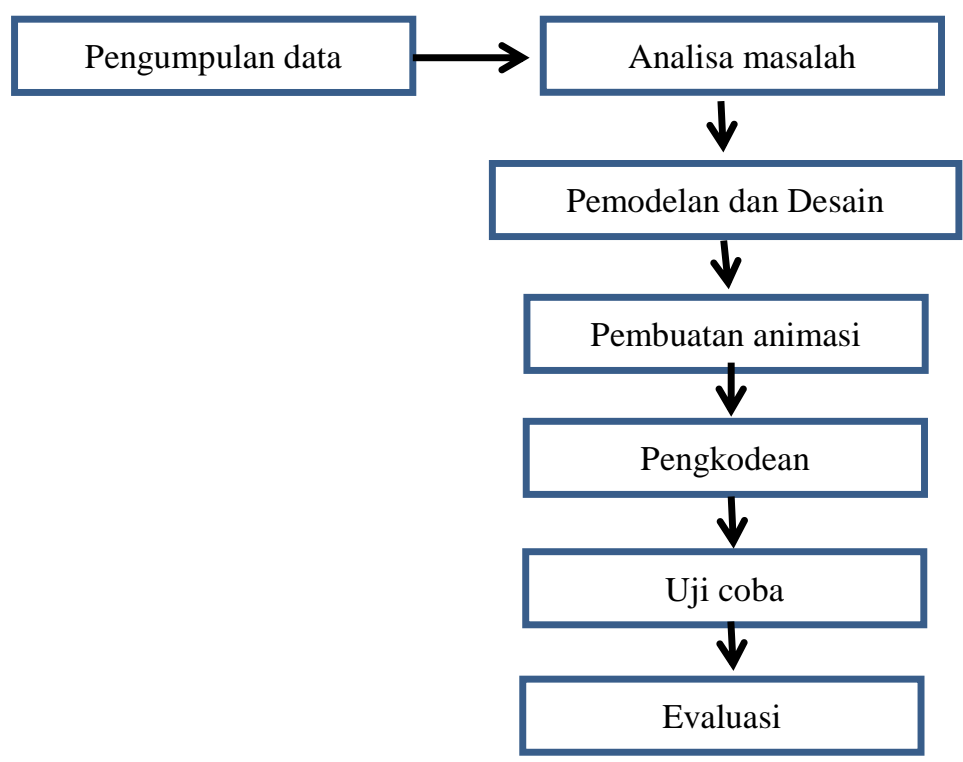

Gambar 1. Tahap pembuatan game edukasi 
Tahap pembuatan game edukasi pada Gambar 1. dapat dijelaskan sebagai berikut:

a. Pengumpulan Data

Pengumpulan data dalam pembuatan game edukasi ini diantaranya mengumpulkan data-data objek yang dibutuhkan serta materi-materi pendukung, baik diperoleh dari Internet maupun buku-buku referensi.

b. Analisa masalah

Analisa masalah yaitu menganalisa masalah tentang hal-hal yang akan diterapkan pada sistem baik analisa fungsionalnya maupun analisa non fungsional untuk pembuatan aplikasi edugame interaktif pengenalan pakaian adat Nasional Indonesia.

c. Pemodelan dan Desain

Pemodelan dilakukan untuk membuat objek karakter boneka yang akan dikenakan pakaian adat Nasional serta desain pakaian adat daerah yang dibutuhkan.

d. Pembuatan animasi

Pembuatan animasi ini untuk menggerakkan objek-objek sehingga membuat aplikasi lebih hidup.

e. Pembuatan coding

Pembuatan coding ini dilakukan untuk menyesuaikan gerakan-gerakan objek menjadi relevan dan akurat serta disesuaikan dengan skor permainan.

f. Uji coba

Uji coba ini dilakukan dengan cara pengisian kuisoner oleh user, dimana hasil dari kuisoner tersebut dapat disimpulkan apakah aplikasi ini dapat diterima menurut kriteria yang diharapkan apa tidak.

g. Evaluasi

Evaluasi ini merupakan hasil kesimpulan uji coba yang telah dilakukan terhadap pengguna yang menyimpulkan apakah aplikasi ini baik atau tidak untuk pengenalan pakaian adat Nasional Indonesia dalam bentuk edugame interaktif.

\section{HASIL DAN PEMBAHASAN}

\subsection{Tampilan Menu Utama dan Tampilan Login}

Pada tampilan menu utama sistem setelah melakukan login kemudian user langsung memulai permainan. Tampilan menu utama terdapat pada Gambar 2.

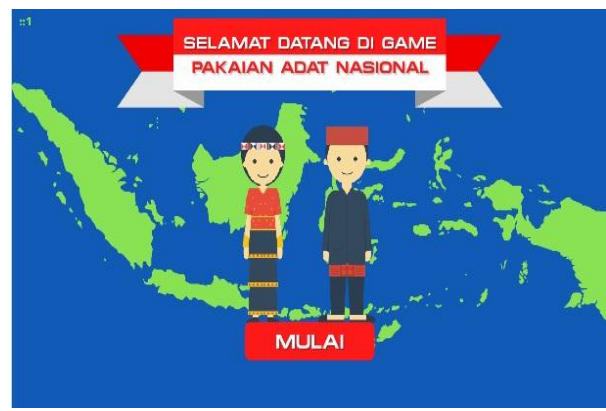

Gambar 2. Menu Utama

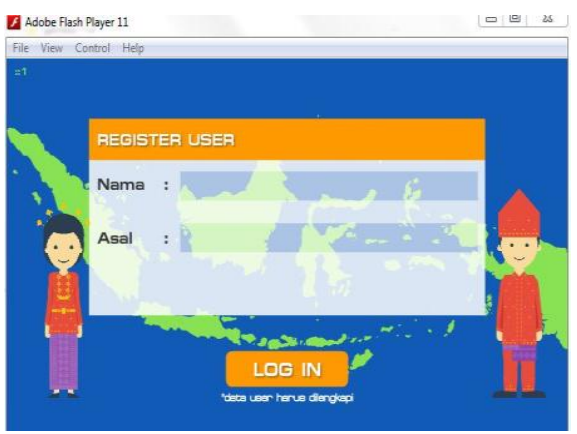

Gambar 3. Login

Pada gambar 2 terdapat tombol "Mulai" yang berfungsi untuk memasuki ke tampilan selanjutnya yaitu tampilan register user. Menu Login pada gambar 3, digunakan oleh user untuk mengakses aplikasi pengenalan pakaian adat nasional. Jika login berhasil dilakukan maka pengguna dapat mengakses tampilan bermain. Tampilan Login ini merupakan form yang diberikan user agar sebelum masuk ke game ini diharuskan mengisikan data user tersebut atau untuk berregistrasi. Jika user tidak mengisi data dengan lengkap maka user tidak dapat masuk ke play game tersebut.

\subsection{Tampilan Play Game}

Tampilan Play Game merupakan tampilan bermain user yang terdapat tombol kembali untuk kembali ke awal menu login, dan tombol selesai untuk menampilkan nilai yang didapatkan. 


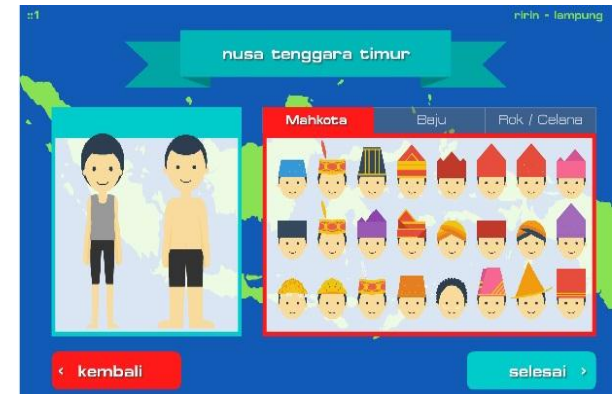

Gambar (a)

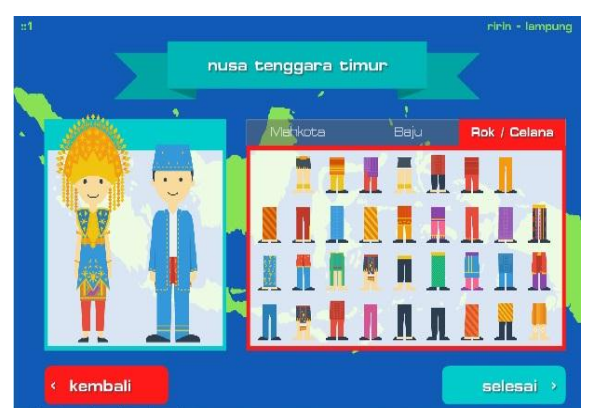

Gambar (b)

Gambar 4. Tampilan play game untuk mahkota (a), dan celana atau kain (b)

Berikut source code program yang digunakan untuk men-drag mahkota, baju, dan celana atau kain dari objek sumber ke objek target:

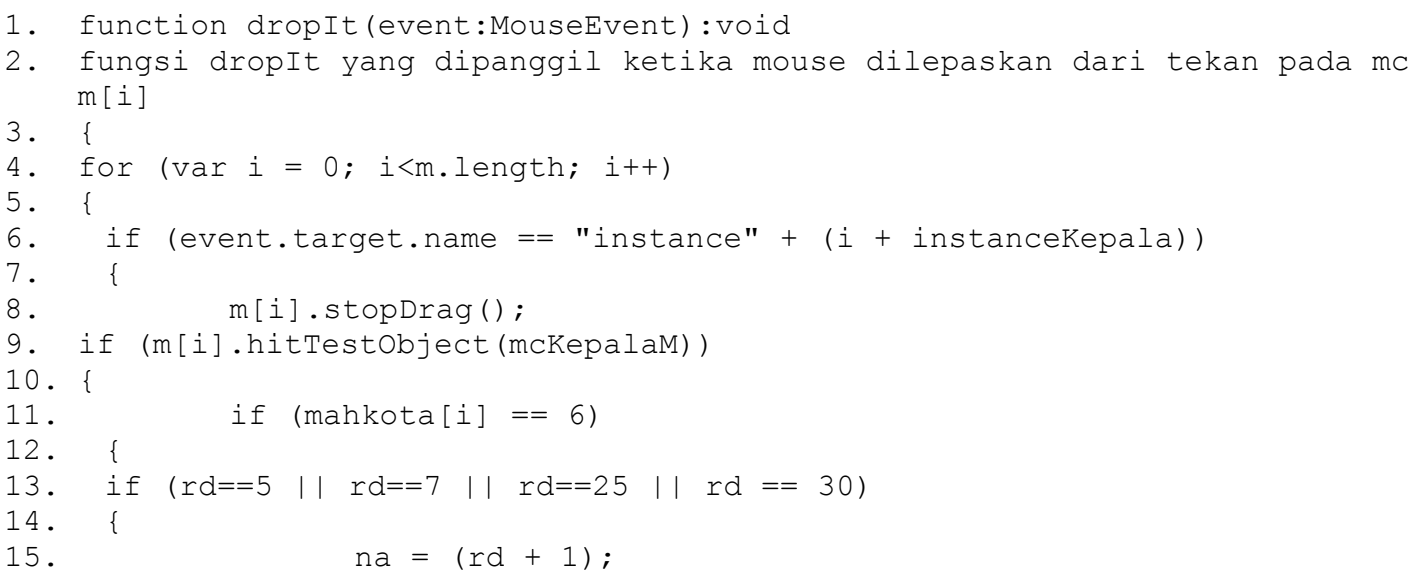

\subsection{Tampilan Hasil Sementara}

Hasil perulangan merupakan hasil sementara permainan dimana user dapat memilih untuk mengulang kembali atau meneruskan permainan. Tampilan hasil sementara seperti ditampilkan pada Gambar 5.

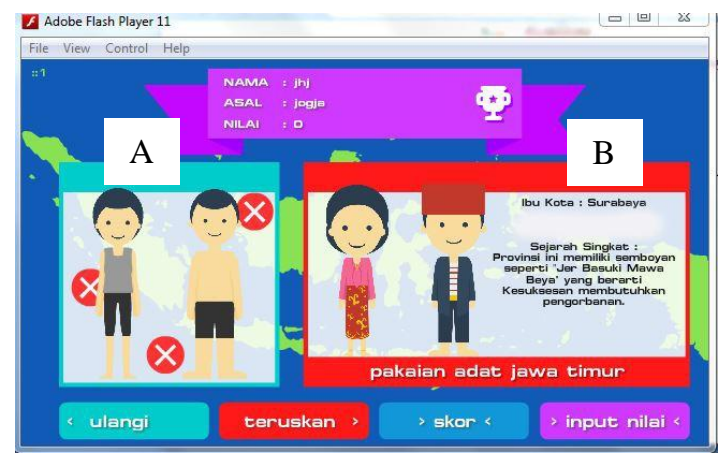

\section{Gambar 5. Hasil perulangan}

Tampilan pada gambar 5 terdapat data diri user dan nilai akhir user yang berfungsi untuk mengetahui nilai poin hasil sementara user. Form A adalah bagian untuk objek yang dirancang oleh user. Sedangkan form B adalah bagian hasil objek pakaian daerah asli sesungguhnya yang benar telah disetting pada sistem. Kolom keterangan berisi sedikit keterangan sesuai dengan hasil pakaian daerah pada form B, seperti nama ibu kota provinsi dan sedikit sejarah dari kota daerah tersebut. Tombol ulangi berfungsi untuk mengulangi permainan dengan nama daerah yang sama untuk memperbaiki nilai. Tombol selesai berfungsi untuk menyelesaikan permainan dengan nilai seadanya dan hasil nilai langsung masuk ke database. Tombol teruskan berfungsi untuk meneruskan permainan dengan nama daerah yang berbeda sesuai random. 


\subsection{Tampilan High Score dan Tampilan Hasil Akhir}

Tampilan gambar 6 berisi high score yang telah masuk ke database, tampilan ini berguna untuk menampilkan hasil dari permainan yang dilakukan pengguna sebelumnya.

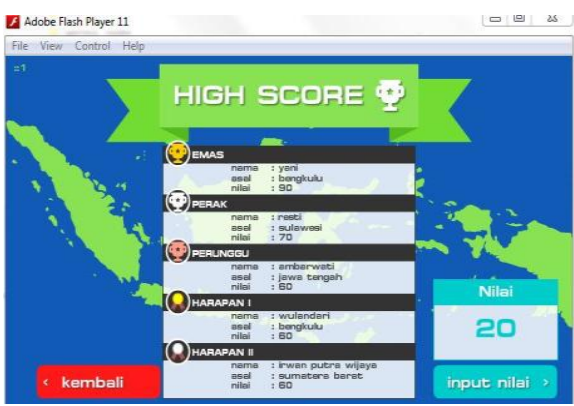

Gambar 6. Tampilan high score

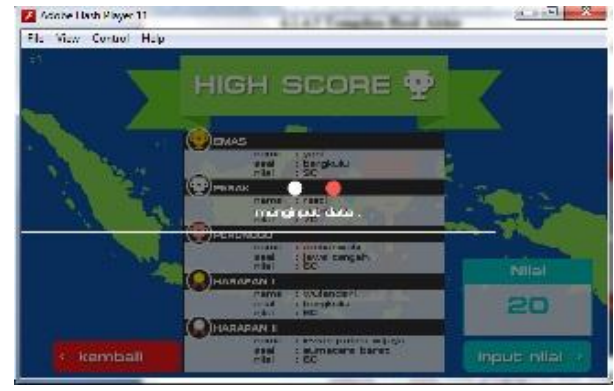

Gambar 7. Hasil akhir penginputan nilai

Proses penginputan nilai akhir user ke database dapat dilihat pada Gambar 7. Tampilan ini digunakan untuk memasukkan data hasil permainan sehingga pengguna game yang skornya tinggi akan masuk pada tampilan high score.

\subsection{Uji Coba Pengguna}

Kriteria interpretasi yang digunakan untuk menguji sistem aplikasi adalah sebagai berikut [3]:

Angka 0\% - 19,99\%: Sangat tidak baik

Angka 20\% - 39,99\%: Tidak baik

Angka 40\%-59,99\%: Cukup

Angka 60\% - 79,99\% : Baik

Angka 80\%-100\%: Sangat baik

Kuisioner yang digunakan terdiri dari 10 pertanyaan mengenai tampilan dan kerja dari sistem terutama apakah sistem ini telah memenuhi beberapa prinsip-prinsip Usability [4], menggunakan skala Likert . Berikut hasil yang didapat dari kuisioner tercantum pada tabel 1.

Tabel 1. Hasil Total Responden pada Pengujian Sistem

\begin{tabular}{ccccccccc}
\hline \multirow{2}{*}{ No } & \multicolumn{4}{c}{ Jumlah jawaban } & Terisi & Error & Total Responden \\
\cline { 2 - 9 } & STB & $\boldsymbol{T B}$ & $\boldsymbol{C}$ & $\boldsymbol{B}$ & $\boldsymbol{S B}$ & & & \\
\hline 1 & 0 & 1 & 3 & 15 & 11 & 30 & 0 & 30 \\
2 & 0 & 0 & 9 & 14 & 7 & 30 & 0 & 30 \\
3 & 0 & 0 & 8 & 13 & 9 & 30 & 0 & 30 \\
4 & 0 & 0 & 11 & 10 & 9 & 30 & 0 & 30 \\
5 & 0 & 0 & 12 & 13 & 5 & 30 & 0 & 30 \\
6 & 0 & 0 & 14 & 11 & 5 & 30 & 0 & 30 \\
7 & 0 & 0 & 13 & 11 & 6 & 30 & 0 & 30 \\
8 & 0 & 0 & 18 & 8 & 4 & 30 & 0 & 30 \\
9 & 0 & 1 & 13 & 11 & 5 & 30 & 0 & 30 \\
10 & 0 & 0 & 10 & 9 & 11 & 30 & 0 & 30 \\
\hline
\end{tabular}

Keterangan

STB = Sangat Tidak Baik, skor 1

TB = Tidak Baik, skor 2

$\mathrm{C}=$ Cukup, skor 3

$\mathrm{B}=$ Baik, skor 4

SB $=$ Sangat Baik, skor 5

Tabel 2 merupakan hasil perhitungan skor yang diperoleh masing-masing pertanyaan. 
Tabel 2. Hasil perhitungan skor yang diperoleh

\begin{tabular}{ccccccc}
\hline & \multicolumn{7}{c}{ Jumlah jawaban $\boldsymbol{x}$ Skor } & & jumlah \\
\hline Pertanyaan & STB & TB & C & B & SB & \\
\hline 1 & 0 & 2 & 9 & 60 & 55 & 126 \\
2 & 0 & 0 & 27 & 56 & 35 & 118 \\
3 & 0 & 0 & 24 & 52 & 45 & 121 \\
4 & 0 & 0 & 33 & 40 & 45 & 118 \\
5 & 0 & 0 & 36 & 52 & 25 & 113 \\
6 & 0 & 0 & 42 & 44 & 25 & 111 \\
7 & 0 & 0 & 39 & 44 & 30 & 113 \\
8 & 0 & 0 & 54 & 32 & 20 & 106 \\
9 & 0 & 2 & 39 & 44 & 25 & 110 \\
10 & 0 & 0 & 30 & 36 & 55 & 121 \\
Jumlah & 0 & 4 & 333 & 460 & 360 & $\mathbf{1 1 5 7}$ \\
\hline
\end{tabular}

Tabel 3 merupakan ringkasan dari tabel 2, sebagai berikut:

Tabel 3. Ringkasan hasil perhitungan

\begin{tabular}{cccc}
\hline Kriteria jawaban & skor & Jumlah jawaban & Jawaban $\boldsymbol{x}$ skor \\
\hline Sangat Tidak Baik & 1 & 0 & 0 \\
Tidak Baik & 2 & 2 & 4 \\
Cukup & 3 & 111 & 333 \\
Baik & 4 & 115 & 460 \\
Sangat Baik & 5 & 72 & 360 \\
Jumlah & & 300 & 1157 \\
\hline
\end{tabular}

Jika semua responden memilih jawaban SB dengan skor 5, maka nilai tertinggi yang bisa diperoleh adalah 30 responden x 10 pertanyaan x 5 kriteria $=1500$, maka interpretasi skor perhitungan dihitung menggunakan indek [1] sebagai berikut:

$$
\begin{aligned}
& \text { Indek }=\frac{\text { Total Jawaban } x \text { skor }}{\text { Nilai tertinggi }} \times 100 \% \\
& \text { Indek }=\frac{1157}{1500} \times 100 \%=77,13 \%
\end{aligned}
$$

Indek hasil persamaan (1) adalah 77,13 \%, maka dapat disimpulkan bahwa pengujian menggunakan kuisioner termasuk dalam kriteria "Baik".

\section{KESIMPULAN} berikut :

Berdasarkan hasil implementasi, pembahasan dan uji coba, dapat disimpulkan beberapa hal sebagai

a. Edugame interaktif pengenalan pakaian adat nasional Indonesia dapat digunakan untuk belajar sekaligus bermain dalam mengenal ciri, motif serta bentuk jenis-jenis pakain adat Nasional Indonesia

b. Berdasarkan hasil kuisioner yang diperoleh bahwa Edugame interaktif pengenalan pakaian adat nasional telah cukup memenuhi kriteria kemampuan kegunaan (usability), keakuratan (accuracy), relevan (relevance), kesesuaian (appropriateness), objektifitas (objectives), umpan balik (feedback).

c. Hasil yang diperoleh dari pengujian para pengguna dan menggunakan beberapa pertanyaan dalam bentuk kuisioner adalah 77,13\% , maka dapat disimpulkan bahwa aplikasi edugame interaktif pengenalan pengetahuan pakaian adat Nasional Indonesia masuk ke kriteria "baik".

\section{DAFTAR PUSTAKA}

[1] Rachman, H. 2012. Game Edukasi. Yogyakarta : Andioffset, hal-6, 25.

[2] Widiastuti,dkk. 2012. Membangun Game Edukasi, Yogyakarta : Andioffset, hal.8-16.

[3] Ali Muhidin, S. Abdurahman, M. 2009. Analisis Korelasi, Regresi dan Jalur dalam Penelitian. Pustaka Setia, Bandung, hal.54-57

[4] Dix, Alan; Finlay,et al. 2004. Human-Computer Interaction, Prentice Hall., chap-7.

[5] Darjat. 2009. Panduan Belajar Flash untuk Pemula, Beraksi dengan Animasi. Media Kom.

[6] Hedratman, H. 2009. The Magic Of Macromedia Director. Bandung. Informatika 